九州大学学術情報リポジトリ

Kyushu University Institutional Repository

Twin-Rotor Wind Turbine Power Performance Compared to a Single-Rotor of the Same Tip-toTip Spacing

Ade l, Mohamed

Future University in Egypt (FUE)

Hisham, Khalid

Future University in Egypt (FUE)

Osama, Mahmoud

Future University in Egypt (FUE)

Awwad, Ade l

Future University in Egypt (FUE)

他

https://doi.org/10.5109/4739242

出版情報 : Proceedings of International Exchange and Innovation Conference on Engineering \& Sciences (IEICES). 7, pp.323-328，2021-10-21. 九州大学大学院総合理工学府 バージョン:

権利関係 : 


\title{
Twin-Rotor Wind Turbine Power Performance Compared to a Single- Rotor of the Same Tip-to-Tip Spacing
}

\author{
Mohamed Adel ${ }^{1}$, Khalid Hisham ${ }^{1}$, Mahmoud Osama $^{1}$, Adel Awwad ${ }^{1}$, Abdelrahman Mohamed ${ }^{1}$, Amira Elkodama $^{1}$, \\ Amr Ismaiel ${ }^{1 *}$ \\ ${ }^{1}$ Future University in Egypt (FUE) \\ ${ }^{*}$ Corresponding author email: amr.mohamed@fue.edu.eg
}

\begin{abstract}
This work introduces a comparison between the conventional single-rotor wind turbine, and a twin-rotor wind turbine. Multi-Rotor wind turbine concept solves many drawbacks of the single-rotor, including ease of transport, installation, and maintenance, in addition to reduced mass of the whole turbine. In this work, the NREL 5MW wind turbine has been scaled down to a single rotor configuration of $40 \mathrm{~cm}$ diameter, and a twin-rotor configuration with two $20 \mathrm{~cm}$ diameter rotors, such that both configurations have the same span. Blade Element Momentum (BEM) theory has been used for simulations to calculate aerodynamic loads and produced power. The BEM algorithm was verified by performing a simulation on the original NREL 5MW rotor and compared to the definition report of the turbine. Simulations on the scaleddown single and twin rotor configurations have shown that although the produced power by the twin-rotor is $50 \%$ of that of the single-rotor, but the thrust load is $50 \%$, rotor torque is $20 \%$, and overall mass is $25 \%$ of the single-rotor configuration. The reduced inertial and aerodynamic load indicate lower cost of energy, and hence the twin-rotor is superior to the singlerotor of the same span size.
\end{abstract}

Keywords: Wind Energy; Twin-Rotor Wind Turbine; Multi-Rotor System

\section{INTRODUCTION}

Wind energy is a clean, and a sustainable source of energy. The world is leaning to increase the use of renewable sources over conventional sources and fossil fuels, to keep a sustainable and environment-friendly energy production. Wind energy is one of the leading sources in the renewable energy field. According to the Global Wind Energy Council (GWEC) Global Wind Report 2021, the total installed wind capacity has increased significantly over the past years. In the year 2020 alone, a total of $93 \mathrm{GW}$ installed wind capacity has been achieved, showing a record of $53 \%$ growth in the year over year growth [1].

Researchers compete to improve the performance of wind turbines in order to harvest the most of wind energy and convert it into usable electrical energy. One way of increasing the capacity of a wind turbine is increasing the rotor diameter. However, the large-sized wind turbines are of great weight, cost, hard to install and maintain [2]. Also, if a single-rotor wind turbine fails, it is a total loss of the capacity of that turbine in a wind farm.

Another way to increase the wind turbine capacity and avoid large-scale wind turbines drawbacks is to install more than one rotor on the same tower. This concept is known as Multi-Rotor System (MRS) Wind Turbines. MRS concept was first introduced by Hoffman in the year 1930, however, back then it was not technically feasible to build a multi-rotor [3]. In the past decade, MRS has started to draw the attention of researchers one more time, since the advances of materials science and analysis methods has made it easier to model and design a support structure for the MRS wind turbine.

Many researchers have studied the performance of MRS wind turbines from the point of view of aerodynamics, power performance, and support structure analysis. Goltenbott et al. have made experimental analysis on the produced power by MRS in different configurations and found some interesting results. They found that a 2-rotor configuration produces $5 \%$ more power than a singlerotor of the same size, and a 3-rotor configuration produces $9 \%$ more power [4]. Those results were advocated by the work of other researchers like
Chasapogiannis et al. who performed Computational Fluid Dynamics (CFD) analysis on a seven-rotor configuration and found a $3 \%$ increase in power per rotor [5]. Also, researchers of the Technical University of Denmark (DTU) have studied the merits of MRS on a 4rotor configuration, and the experiment agreed with the simulations on an increase around $2 \%$ in the power produced per rotor [6].

In the light of MRS wind turbines advantages, Ismaiel and Yoshida have made an aeroelastic analysis on a $\mathrm{T}$ shaped tower for a twin-rotor wind turbine [7]. The rotor in that work was the original National Renewable Energy Laboratory (NREL) 5MW wind turbine [8]. This work adopts the same tower concept, a T-shaped tower with two rotors in the same plane, however, on a scaled-down version of the NREL 5MW rotor.

In the following sections, the problem definition and scaling down will be shown, followed by the aerodynamic model for power calculations, verification of the aerodynamic model, then simulation of the scaleddown single-rotor and twin-rotor, their results, and finally a conclusion section which highlights the outcomes of this work.

\section{PROBLEM DEFINITION AND SCALING- DOWN}

\subsection{Problem Definition}

A Multi-Rotor Wind Turbine introduces lower weight of the rotors and accordingly lower cost, with logistic advantages like the reduced cost of transportation, ease of installation and maintenance [3]. With those advantages, the aim of this work is to compare the power performance of a single-rotor to a twin-rotor wind turbine. This work introduces the aerodynamic calculations to anticipate the produced power by each configuration, however, the ultimate goal of the research is to conduct experiments to validate the results of the current work, and hence comes the limitations to the size of the rotor.Experiments will be carried on in the wind tunnel available in the workshops of the Future University in 
Egypt (FUE). This wind tunnel, shown in Figure 1, has a limitation of the test area where the rotors should be placed, such that the prototype dimensions should not exceed $40 \mathrm{~cm} * 40 \mathrm{~cm}$ due to boundary conditions and flow attachment to the walls.

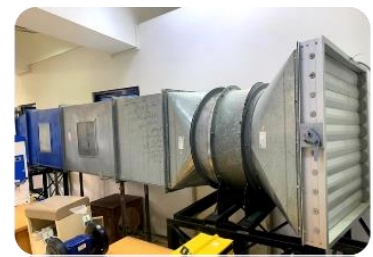

(a)

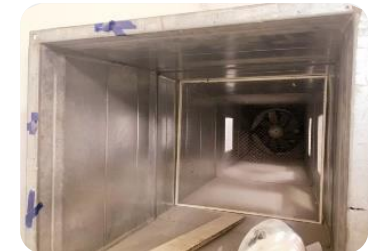

(b)
Fig. 1. Wind Tunnel available in Future University in Egypt (FUE): (a) External view of the tunnel, (b) Internal view of the tunnel's test section.

With the size limitation of the wind tunnel, a scaleddown version of the NREL 5MW rotor should be used for analysis. Since the maximum size of the rotor diameter should not exceed $40 \mathrm{~cm}$, two configurations for single-rotor and twin-rotor were made.

It has been decided that the common parameter to be taken for comparison, is the tip-to-tip spacing; the distance from the tip of a blade from each rotor in the twin configuration, will be the same as the single-rotor configuration; $40 \mathrm{~cm}$.

Aerodynamic simulations using Blade Element Momentum (BEM) theory will be performed in order to compare the power output of a single, $40 \mathrm{~cm}$ diameter rotor, to a twin $20 \mathrm{~cm}$ rotor 2-rotors configuration.

\subsection{Scale-Down of NREL 5MW Rotor}

There are different types of scale-down of wind turbines: geometric scaling, dynamic scaling, and empirical scaling. Each type applies for certain cases depending on the required complexity of the problem.

In the scope of this work, the restriction on the size of the rotor requires the simplest type, geometrical scaling, also known as zero-order scaling. Dimensions of the rotor are simply multiplied by the scaling factor $[9,10]$.

The original dimensions and structural properties of the NREL 5MW rotor are shown in Table 1.

Table 1. Properties of the Original NREL 5MW Wind Turbine

\begin{tabular}{lr}
\hline \hline Property & Value \\
\hline Blade Length $(\mathrm{m})$ & 63 \\
Rotor Diameter $(\mathrm{m})$ & 128 \\
Tower Height $(\mathrm{m})$ & 87 \\
Rotor Mass $(\mathrm{kg})$ & 110,000 \\
Nacelle Mass $(\mathrm{kg})$ & 240,000 \\
Cut-in Wind Speed (m/s) & 3 \\
Rated Wind Speed (m/s) & 11.4 \\
\hline \hline
\end{tabular}

For geometric scaling, the dimensions are proportional to the length, while mass is proportional to the length cubed. The parametric length in the scaling process is the rotor diameter $\mathrm{D}$, hence, mass is directly proportional to the cube of the rotor diameter. $\left(\mathrm{m} \alpha \mathrm{D}^{3}\right)$.

The two configurations subject to study for this work are a single rotor of rotor diameter $40 \mathrm{~cm}$, and a twin-rotor of rotor diameter $20 \mathrm{~cm}$ each. This is to abide by the restriction of the $40 \mathrm{~cm} * 40 \mathrm{~cm}$ test area of the available wind tunnel available in FUE's lab. Table 2 shows a comparison between the single-rotor Vs. the twin-rotor configuration.

Table 2. Comparison Between Properties of Single-Rotor Vs. Twin-Rotor Wind Turbine Configurations

\begin{tabular}{lcc}
\hline \hline Property & $\begin{array}{c}\text { Single- } \\
\text { Rotor }\end{array}$ & $\begin{array}{c}\text { Twin- } \\
\text { Rotor }\end{array}$ \\
\hline Blade Length $(\mathrm{m})$ & 0.197 & 0.098 \\
Rotor Diameter $(\mathrm{m})$ & 0.4 & 0.2 \\
Tower Height $(\mathrm{m})$ & 0.27 & 0.136 \\
Rotor Mass $(\mathrm{kg})$ & $3.35^{*} 10^{-3}$ & $0.419^{*} 10^{-3}$ \\
Nacelle Mass $(\mathrm{kg})$ & $7.32^{*} 10^{-3}$ & $0.915^{*} 10^{-3}$ \\
Cut-in Wind Speed (m/s) & 3 & 3 \\
Rated Wind Speed (m/s) & 11.4 & 11.4 \\
\hline \hline
\end{tabular}

It can be noted that there is a significant decrease in the total mass of the rotor for the twin-rotor configuration of a total mass $2 * 0.419 * 10^{-3}=0.839 * 10^{-3} \mathrm{~kg}$ compared to a mass of $3.35^{*} 10^{-3} \mathrm{~kg}$ of the single-rotor configuration. This vast difference saves more material and hence cost for the whole wind turbine. Also, the inertial loads on the tower are significantly decreased.

It can also be noted that the values of cut-in wind speed, which is defined as the minimum wind speed for power production, and the rated wind speed defined as the speed at which the rated power is reached, are kept constant. Those values are the same as the original NREL 5MW rotor since they are design properties which should not be affected by the geometric scaling.

In the following section, the mathematical model used for calculations will be introduced, also, the verification of the original model calculations to the NREL 5MW definition report [8].

\section{MATHEMATICAL MODEL}

\subsection{Blade Element Momentum (BEM) Theory}

Blade Element Momentum (BEM) theory was used for the anticipation of the aerodynamic loads on the rotor, as well as the produced power. Classical BEM, which does not account for the unsteadiness in the wind, is sufficient to calculate steady load, and determine the expected annual power production of a wind turbine, and also the rotor loads like thrust force and torque [11].

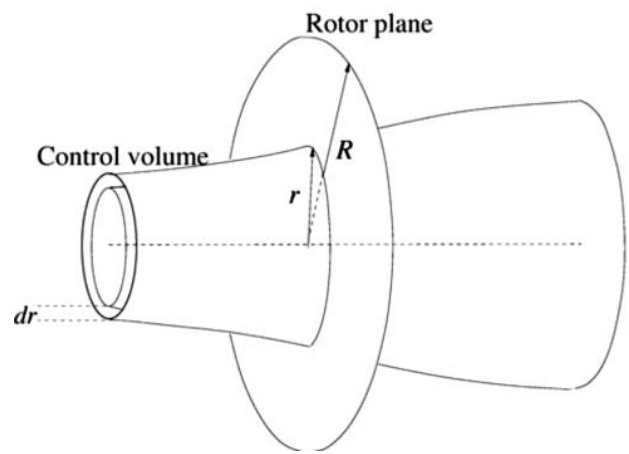

Fig. 2. Annular Element Used in Classical BEM Theory [11]

The rotor is divided into annular elements of size $d r$ along the blade length, and the main two assumptions in this theory is that there is no radial dependency between the elements, and that the theory sees the rotor as if it has an 
infinite number of blades. Figure 2 shows the annular element taken into consideration in classical BEM theory.

Figure 3 shows the cross-section of the blade at any annular element, and the loads on that airfoil.

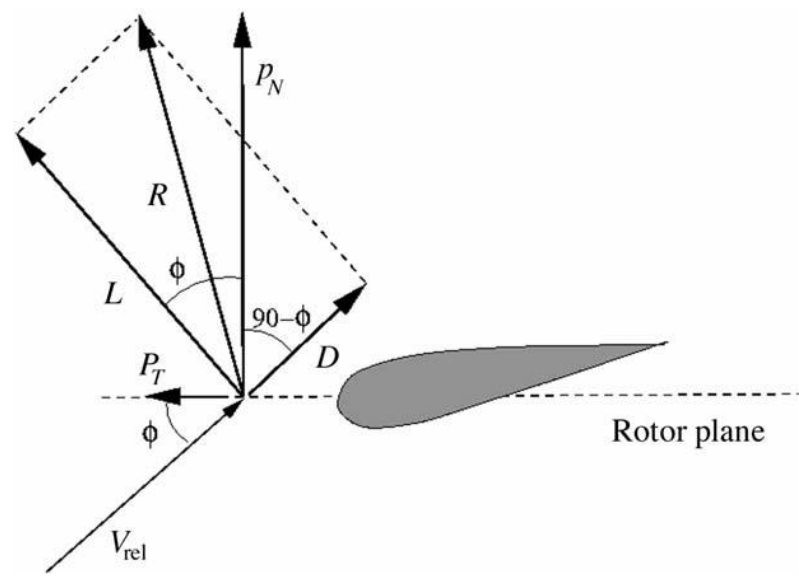

Fig. 3. Loads on a Cross-Section Airfoil of the Blade [11]

The lift force (L) and drag force (D) at each annular element can be calculated according to the following equations:
$L=\frac{1}{2} \rho V_{\text {rel }}^{2} c C_{l}$
Eq. 1
$D=\frac{1}{2} \rho V_{r e l}^{2} c C_{d}$
Eq. 2

Where $\rho$ is the air density, $V_{\text {rel }}$ is the relative wind speed to the cross-section airfoil, $c$ is the section's chord length, $C_{l}$ is the local coefficient of lift, and $C_{d}$ is the local coefficient of drag.

After the lift and drag forces are calculated, the loads per length normal to the plane of rotation $\left(\mathrm{P}_{\mathrm{N}}\right)$ and tangential to the plane of rotation $\left(\mathrm{P}_{\mathrm{T}}\right)$ can be calculated as follows:
$P_{N}=L \cos \varphi+D \sin \varphi$
Eq. 3
$P_{T}=L \sin \varphi-D \cos \varphi$
Eq. 4

Where $\varphi$ is the local flow angle on the airfoil.

Hence, the thrust load per blade can be calculated by integrating the normal load $P_{N}$ along the blade length, and the rotor torque can be calculated by integration the moment of the tangential force $P_{T}$ along the blade length. The total thrust force $T$ on the rotor of $B$ number of blades can be calculated by simply multiplying the number of blades $B$ with the thrust per blade, and so does the torque $M$. This can be expressed as follows:
$d T=B P_{N} d r$
$d M=r B P_{T} d r$
Eq. 5
Eq. 6

Finally, the power produced by the rotor is calculated by multiplying the rotor's rotational speed $\omega$ to the rotor torque $M$, expressed as follows:
$d P=\omega d M$
Eq. 7

Prandtl's tip loss factor was considered to account for the assumption of infinite blades in the rotor made in the classical BEM theory. Also, Glauert correction was made for the induction factor which represents the induced velocity due to rotor wakes. Those corrections give more accurate results compared to the reference values.

\subsection{Verification of the classical BEM algorithm}

In order to obtain trustworthy results for the single and twin-rotor configurations of interest in this study, the algorithm made to apply the blade element momentum theory should first be verified by the original NREL $5 \mathrm{MW}$ wind turbine.

Simulation has been made using an in-house code for BEM method, using the same simulation conditions as in the NREL 5MW definition report [8]. Variable wind speeds were used in the simulation, starting from the cutin wind speed of $3 \mathrm{~m} / \mathrm{s}$ till the rated wind speed of 11.4 $\mathrm{m} / \mathrm{s}$. Beyond the rated speed, pitch control should be applied on the blades, and since the scope of this work does not include pitch control, hence, only below rated wind speed will be considered for the study.

Three main outcomes were calculated and compared to the NREL 5MW definition report. These outcomes are the rotor Thrust force, rotor Torque, and rotor Power. Figures 4 to 6 show the results of the rotor loads compared to the definition report.

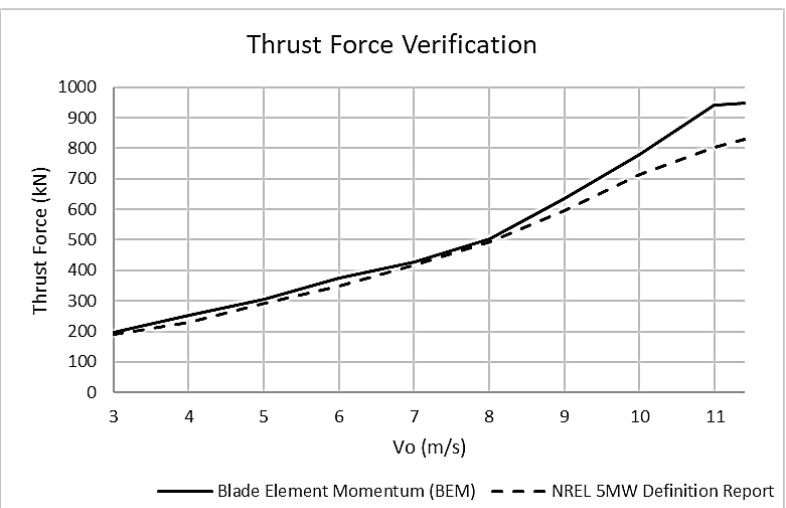

Fig. 4. Thrust Force Verification: BEM Vs. Definition Report

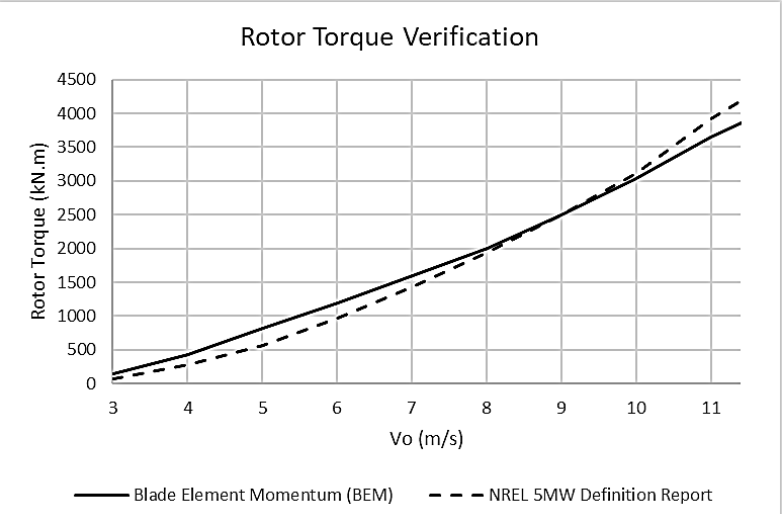

Fig. 5. Rotor Torque Verification: BEM Vs. Definition Report

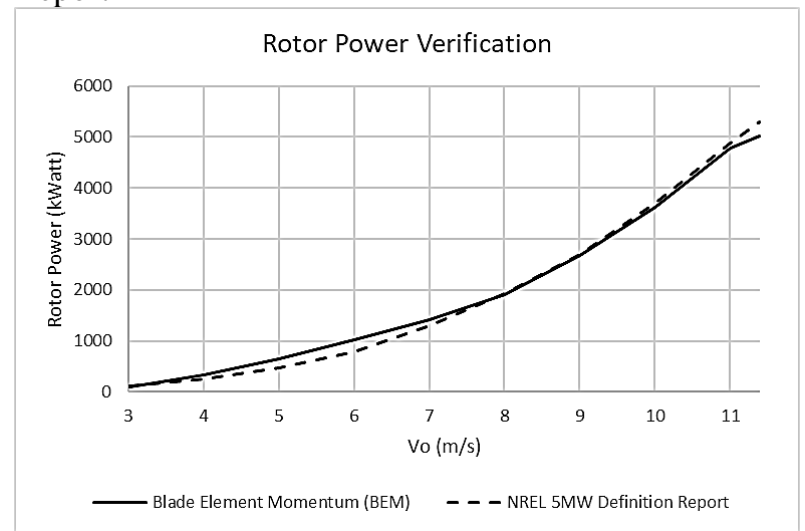

Fig. 6. Rotor Power Verification: BEM Vs. Definition Report 
It can be noted that there are some discrepancies between the simulation and the reference definition report. These discrepancies are due to difference in calculation methods adopted in the definition report compared to the classical BEM theory adopted in this work. However, these discrepancies have a maximum deviation value of $14.7 \%$ in the Thrust force at $11.4 \mathrm{~m} / \mathrm{s}$ wind speed, but the trend and values of the different loads are very comparable, and hence, BEM code is sufficient for simulation of the scaled-down configurations of the wind turbine.

\section{RESULTS AND DISCUSSION}

In this section, a comparison between the single-rotor and twin-rotor configurations will be made. The design parameters of the original NREL 5MW are kept constant. Those key parameters are the cut-in wind speed, rated wind speed, tip speed ratio, and coefficient of power.

The three main loads taken into consideration for comparison are the Thrust Force, Rotor Torque, and Rotor Power.

The flow is considered to be laminar for simplicity at this stage. However, turbulent wind conditions affect the fatigue loads and hence the lifetime of the wind turbine $[12,13]$, hence, it should be considered later for a more thorough study of the configurations' comparison.

The expected rated power of the rotor can be calculated from the ideal power equation shown below.

$$
P=\frac{1}{2} \rho V^{3} A C_{P} \quad \text { Eq. } 8
$$

Such that $\rho$ is the air density taken as $1.225 \mathrm{~kg} / \mathrm{m}^{3}, V$ is the wind speed, $A$ is the rotor covered area, and $C_{P}$ is the coefficient of power.

For the expected rated power, the rated wind speed of $11.4 \mathrm{~m} / \mathrm{s}$, and the rated coefficient of power of 0.482 are used for calculations.

For the single-rotor configuration, with rotor diameter of $40 \mathrm{~cm}$, the expected ideal rated power is 54.9 Watts, while for twin-rotor configuration with a rotor diameter $20 \mathrm{~cm}$, the ideal rated power is 13.7 Watts/rotor, or 27.5 Watts for the twin-rotor turbine.

Since the actual value of produced power is different due to the existence of wakes which induce wind speeds at the blade tip, the actual rotor power is expected to be of less value.

Simulation conditions are shown in Table 3.

Table 3. Simulation Conditions

\begin{tabular}{lr}
\hline \hline Condition & Value \\
\hline Air Density $\left(\mathrm{kg} / \mathrm{m}^{3}\right)$ & 1.225 \\
Minimum Wind Speed $(\mathrm{m} / \mathrm{s})$ & 3 \\
Maximum Wind Speed $(\mathrm{m} / \mathrm{s})$ & 11.4 \\
Wind Speed Step Value $(\mathrm{m} / \mathrm{s})$ & 1 \\
Pitch angle $\left({ }^{\circ}\right)$ & 0 \\
Time Step $(\mathrm{s})$ & 0.01 \\
Number of Iterations & 1500 \\
\hline \hline
\end{tabular}

Figure 7 shows the comparison between the rotor thrust of single-rotor configuration Vs. twin-rotor configuration. The shown thrust of twin-rotor configuration is for the whole turbine, i.e., the whole thrust on tower-top by both rotors.

The comparison of thrust force between two configurations, show a significant decrease in the values of the thrust force. For the twin-rotor, the values of thrust force are as low as half of those of single-rotor configuration. This decrease is in favor of the tower design, since the loads are significantly smaller, the tower is subject to less loads, and hence can be designed for such case. Accordingly, the cost of the tower can be decreased based on the new design which allows more flexibility and uses less material.

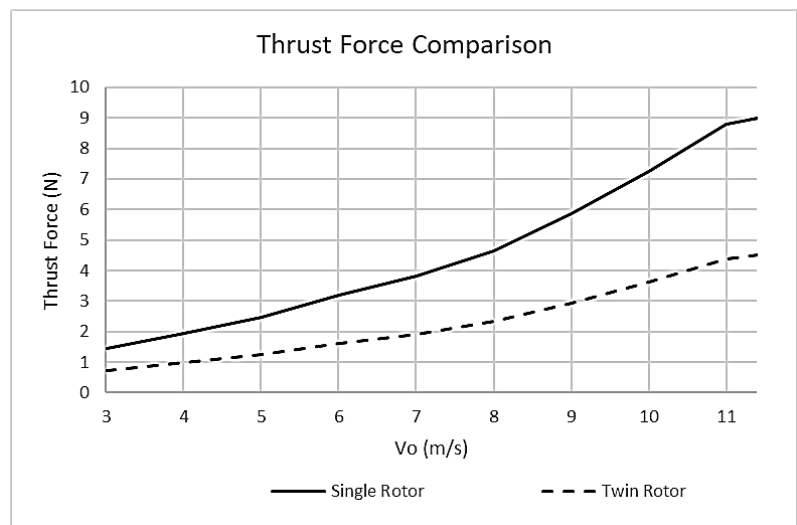

Fig. 7. Thrust Force Comparison - Single-Rotor Vs. Twin-Rotor Configuration

Figure 8 shows the comparison of rotor torque for the single-rotor configuration, and the total torque on towertop induced by the two rotors of a twin-rotor configuration.

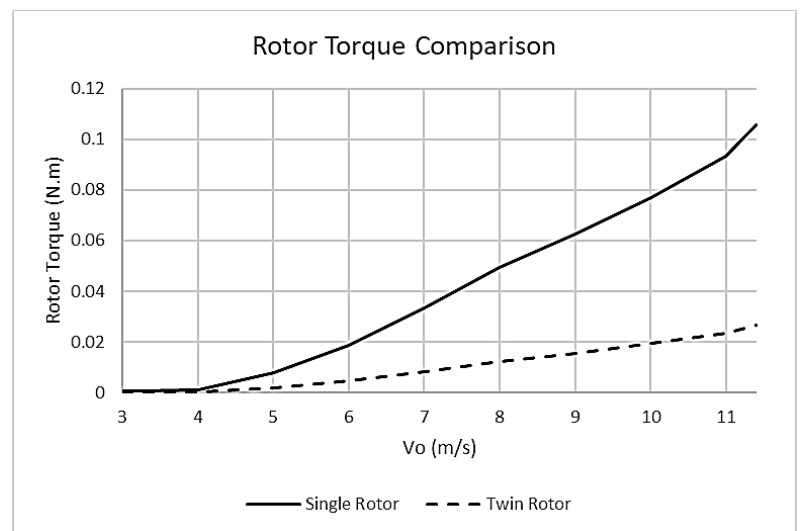

Fig. 8. Rotor Torque Comparison - Single-Rotor Vs. Twin-Rotor Configuration

The decrease in the rotor torque is much higher than the ratio of decrease in the thrust load. The values of the total turbine torque for both rotors of a twin-rotor configuration are as small as $20 \%$ of those of the singlerotor. This result shows a great advantage of the twinrotor configuration. For a tower with non-circular crosssection, it can be designed to stand for the thrust load, however, torque loads can be considered to be insignificant in comparison. This allows for more reduction in the materials used, hence reduce the total weight of the turbine, and accordingly the cost.

This cost had a direct impact on the cost of energy, not only the initial cost. The cost of energy depends on many factors including the initial cost, installation cost, and maintenance cost together with the running cost. If the initial cost is reduced, and the tower and rotor are of lighter weight, the installation and transportation costs will be reduced as well. The effect of lower weight and 
lower aerodynamic loads are considered to be exponential.

The most important factor of comparison in this study is the rotor power produced by each configuration. This comparison is shown in Figure 9, where the produced power for single-rotor configuration is compared to the total power produced for both rotors of the twin-rotor configuration, not taking into account the effect of aerodynamic interaction between the rotors.

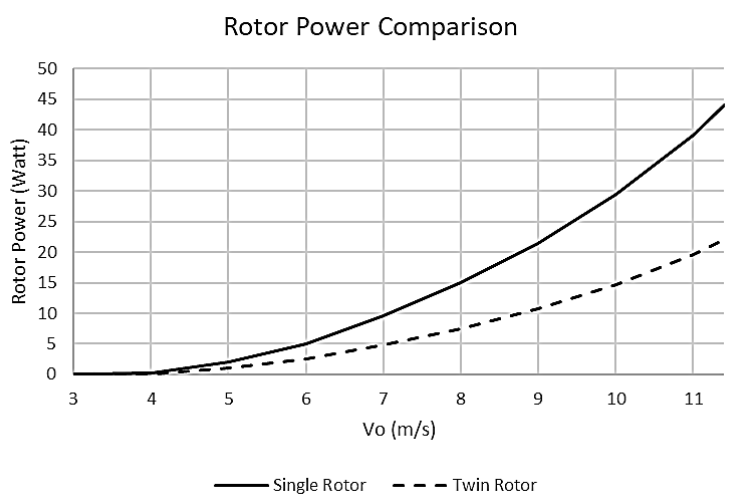

Fig. 9. Rotor Power Comparison - Single-Rotor Vs. Twin-Rotor Configuration

The comparison shows that the single-rotor configuration produces almost the double of the power produced by the twin-rotor configuration. That was expected from the calculations of the ideal power produced which was 54.9 Watts for single-rotor compared to 27.5 Watts for the twin-rotor configuration. The values from the simulation at rated wind speed of $11.4 \mathrm{~m} / \mathrm{s}$ show less values since there are corrections due to the wakes induced behind the rotor, however, the results are comparable.

This result may seem negative at the first look to the curve, however, with a thorough look into all the parameters considered in the study, the twin-rotor configuration is superior to the single-rotor.

Figure 10 shows a summary of the comparison between single-rotor and twin-rotor configurations.

Single Vs. Twin Rotor

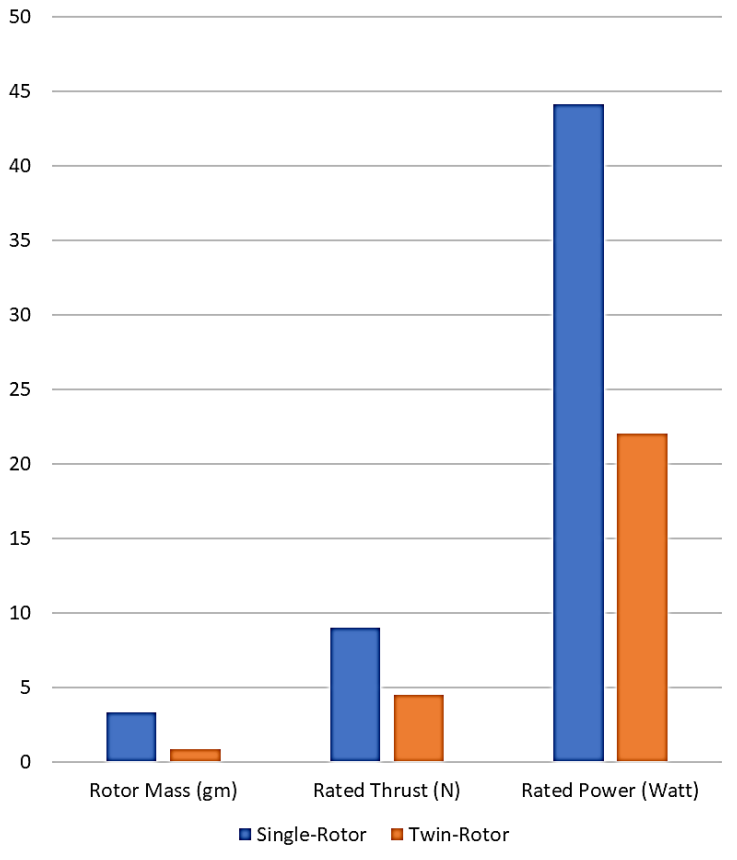

Fig. 10. Summary of Single-Rotor Vs. Twin-Rotor Comparison

Comparing all parameters, the total mass of both rotors in a twin-rotor configuration is $0.839 * 10^{-3} \mathrm{~kg}$ compared to $3.35^{*} 10^{-3}$ for the single-rotor, which is $25 \%$ of the total mass. The thrust loads of the twin-rotor are as low as $50 \%$ of the thrust for a single-rotor, and the torque loads are as low as $20 \%$ of the single-rotor configuration.

With all parameters considered, the reduced weight and aerodynamic loads of the twin-rotor configuration results in a lower Cost of Energy (COE) compared to singlerotor configuration. In other words, 1 watt of power produced by the twin-rotor configuration is cheaper than that produced by the single-rotor configuration.

Based on these results, the twin-rotor configuration is favorable and more economic than the single-rotor configuration.

\section{CONCLUSION}

In this work, a comparison between a single-rotor and a coplanar twin-rotor has been made. Scaling-down of the NREL 5MW rotor has been done based on geometric scaling method. Due to restriction of the available wind tunnel, the span size of both configurations should not exceed $40 \mathrm{~cm}$. Hence, the single-rotor configuration has a $40 \mathrm{~cm}$ diameter rotor, while for the twin-rotor configuration, the rotor has a diameter of $20 \mathrm{~cm}$.

Classical Blade Element Momentum (BEM) method has been used for calculations of aerodynamic loads. In order to verify the algorithm before performing the analysis on the study of interest, simulations have been made on the original NREL 5MW rotor. The results were compared to the definition report and were very similar, hence, the algorithm is sufficient for further analysis.

After the algorithm has been verified, simulations on both single-rotor and twin-rotor configurations of the scaled-down rotor have been carried on. Simulation results showed that rotor thrust load of the twin-rotor configuration are as low as $50 \%$ of that of the single-rotor configuration. Torque loads showed a maximum of $20 \%$ of the torque on a single-rotor, and the produced power was around half the value of that of a single-rotor.

In addition to the reduced mass of the twin-rotor turbine, the reduction in aerodynamic loads make it cheaper to design a support structure for the twin-rotor than the tower of single-rotor. Also, the rotor itself is lighter and hence cheaper. So, overall cost will be reduced and hence the cost of energy of a twin-rotor is cheaper compared to a single-rotor configuration.

Since this research is ongoing, it is suggested to conduct experiments to validate the results of this work. Also, for a more thorough comparison, two more configurations can be investigated.

First, a Quad-rotor configuration, where the total span of the turbine is still within the $40 \mathrm{~cm} * 40 \mathrm{~cm}$ restriction of the wind tunnel. This configuration is expected to produce the same total rated power, however, the mass is expected to be reduced by $50 \%$. These results can also be validated by wind tunnel experiments.

Second suggested configuration is a twin-rotor with larger rotor diameters such that the total power produced by this configuration is the same as the single-rotor configuration. The expected mass of this configuration shows a reduction of $30 \%$ compared to the single rotor. 
However, results of this simulation cannot be validated using the available wind tunnel since the total span will exceed the limit. If improvements are made on the existing wind tunnel, or another wind tunnel became available to use, validation of this configuration's results will be possible.

\section{REFERENCES}

[1] Global Wind Energy Council (GWEC), Global Wind Report, Brussels, Belgium, 2021.

[2] M. Hofmann, I.B. Sperstad, Will $10 \mathrm{MW}$ wind turbines bring down the operation and maintenance cost of offshore wind farms?, Energy Procedia, 53, 2014, 231-238.

[3] P. Jamieson, Innovation in Wind Turbine Design, Wiley-Blackwell, Chichester, UK, 2011.

[4] U. Goltenbott, U. Ohya, S. Yoshida, P. Jamieson, Aerodynamic interaction of diffuser augmented wind turbines in multi-rotor systems. Renew. Energy, 112, 2017, 25-34.

[5] P. Chasapogiannis, J.M. Prospathopoulos, S.G. Voutsinas, T.K. Chaviaropoulos, Analysis of the aerodynamic performance of the multi-rotor concept. J. Phys. Conf. Ser., 524, 2014, 012084.

[6] M.P. Van der Laan, S.J. Andersen, N.R. García, N. Angelou, G.R. Pirrung, S. Ott, M. Sjöholm, K.H. Sørensen, J.X.V Neto, M. Kelly, Power curve and wake analyses of the Vestas multi-rotor demonstrator. Wind Energy Science, 44, 2019.

[7] A. Ismaiel, S. Yoshida, Aeroelastic Analysis of a CoPlanar Twin-Rotor Wind Turbine, Energies, 12, 2019, 1881.

[8] J. Jonkman, S. Butterfield, W. Musial, G. Scott, Definition of a 5-MW Reference Wind Turbine for Offshore System Development; NREL Technical Report TP-500-38060; National Renewable Energy Lab: Golden, CO, USA, 2009.

[9] P. Verma, Multi Rotor Wind Turbine Design and Cost Scaling. Master's Thesis, University of Massachusetts Amherst, Amherst, MA, USA, September 2013.

[10] G.M. Mate, Development of a Support Structure for Multi-Rotor Wind Turbines. Master's Thesis, University of Massachusetts Amherst, Amherst, MA, USA, September 2014.

[11] M.O.L. Hansen, Steady BEM Model. In Aerodynamics of Wind Turbines, $2^{\text {nd }}$ ed.; Earthscan: London, UK, 2008.

[12] A. Ismaiel, S. Metwalli, B. M. N. Elhadidi, Fatigue Analysis of an Optimized HAWT Composite Blade, $2^{\text {nd }}$ International Exchange and Innovation Conference on Engineering \& Sciences (IEICES), Fukuoka, Japan, 2016.

[13] A. Ismaiel, S. Yoshida, Study of turbulence intensity effect on the fatigue lifetime of wind turbines, $3^{\text {rd }}$ International Exchange and Innovation Conference on Engineering \& Sciences (IEICES), Fukuoka, Japan, 2017. 